\title{
The Right and Wrong of Growing Old: Assessing the Argument from Evolution
}

\author{
Bennett Foddy
}

Received: 21 November 2011 / Accepted: 23 January 2012 /Published online: 28 February 2012

(C) Springer-Verlag 2012

\begin{abstract}
One argument which is frequently levelled against the enhancement of human biology is that we do not understand the evolved function of our bodies well enough to meddle in our biology without producing unintended and potentially catastrophic effects. In particular, this argument is levelled against attempts to slow or eliminate the processes of human ageing, or 'senescence', which cause us to grow decrepit before we die. In this article, I claim that even if this argument could usefully be applied against attempts to enhance other human traits, it cannot be valid in the case of attempts to enhance the various processes that constitute senescence. I begin by reviewing the biology of ageing to show how it consists of a number of unrelated traits. Then, following the arguments of a number of evolutionary biologists, I explain that every one of these traits is a product of evolutionary 'neglect' rather than 'intent'. Finally, I consider the strongest version of the argument against enhancing senescence, which acknowledges these facts about the evolution of ageing but insists that we have nevertheless have prudential reasons to avoid enhancement wherever there is some uncertainty about the genetics or evolutionary function of a trait. I provide two reasons for rejecting this version of the argument as well, even in the case of human senescence, where such uncertainty is currently significant.
\end{abstract}

Keywords Ageing $\cdot$ Human enhancement $\cdot$ Evolution $\cdot$ Ethics $\cdot$ Genetics $\cdot$ Senescence

Over the past 150 years, human lifespan in developed countries doubled, primarily due to the elimination of infectious disease through sanitation, medical hygiene, antibiotics, and widespread vaccination programmes (Vaupel 2010). And while there may be hard biological limits to how long we can live without employing more radical strategies, human lifespan - at least for the time being - continues to increase through the development and application of everyday medical technology.

B. Foddy $(\triangle)$

Institute for Science \& Ethics, University of Oxford,

Suite 8, Littlegate House, 16-17 St. Ebbes St, Oxford OX1 1PT, UK

e-mail: bennett.foddy@philosophy.ox.ac.uk 
In light of this, a range of practical arguments have been advanced in favour of dying at some particular age. For example, some philosophers have argued that we are each due a fixed proportion of the world's resources, including food and space, and that any attempt to exceed this allotment constitutes an injustice upon future generations. John Harris calls this the 'fair innings' argument, since it is often said that very old people have a lesser claim on additional life when they have already had a fair innings (Harris 1970). Others worry that death is one of the major forces for equality in the world, and that welfare disparities will be worsened if we some people can afford to postpone or even avoid dying of old age (Mauron 2005). And Bernard Williams argues that life simply becomes worthless when we have lived beyond a certain length of time (Williams 1976). And so on. I take all these arguments to be separate from the question of whether or not we ought to grow old, or 'senescent', before we die of old age.

It is certainly not the case that long life and long youth go hand-in-hand. Human beings might have evolved with very different patterns of senescence. The American lobster (Hormarus americanus) has a similar lifespan to humans, but it grows for the entire duration of its life, and even very old specimens show few observable symptoms of senescence when they eventually die of old age (Bodnar 2009). If lobsters can live to be 80 years old without becoming senescent, then so could we-at least in theoryand so there is now a number of serious scientific projects underway which aim to identify means of slowing, or even halting, the processes of human senescence. ${ }^{1}$

Indeed, according to the demographer James Vaupel, medical science has already unintentionally delayed the ageing process by 10 years for the average person (Vaupel 2010). Compared to people living in the nineteenth century, we have 10 extra years of mobility; 10 extra years without heart disease, stroke, or dementia; and 10 years of feeling subjectively as though we are in good health. But emerging medical technologies threaten to have a more drastic impact on the rate at which we age. And while a number of the moral objections to these technologies have focused on the costs associated with living longer lives, somewhat less has been written about the ethics of choosing against the processes of ageing.

Arguments in favour of ageing nearly always draw some kind of link between what is natural and what is good, and reject any move to defeat a natural phenomenon as a move away from goodness. And there has certainly been a great deal of support in politics and the popular press for a straightforward, naïve argument of this kind. However, as Arthur Caplan has pointed out, if ageing is a natural process then so are cancer, heart disease, and even infectious disease, the three main sources of human

\footnotetext{
1' It is not yet known how far human lifespan and 'youthspan' may be improved. There are various naturally imposed limits to human lifespan, and it is not always obvious how these can be addressed (if at all). For example, there is a 'hard' limit to the number of times a cell may reproduce which is related to the length of the telomeres on the ends of our chromosomes. For this reason, there will be limits to how far longevity and youth can be improved using existing kinds of medical interventions. However, there are at least hypothetical treatments to address even the hard limits of cellular senescence. For example, lobsters have evolved to express high levels of telomerase, an enzyme which restores these telomeres, overcoming the normal limits on cellular replication. There are good indications that human cells could benefit from the exact same mechanism using gene therapy (Fossel 1998; Tomás-Loba et al. 2008). However, even without changing our genes, there is no reason to think we are anywhere near these hard limits at present (Olshansky and Carnes 2001). Even without making direct interventions on the processes of senescence, there is still progress to be made in both life and youth.
} 
suffering and mortality (Caplan 2005). Thus, philosophers who wish to argue in support of ageing by appealing to what is natural - without also supporting the total abolition of medicine - must flesh out their explanations of what makes ageing natural and what makes the natural (so construed) good.

Contemporary philosophical arguments of this kind take one of three forms. The first, which is promoted by Leon Kass, is that the ageing process makes an elderly person's death less painful for the survivors around her, since it gradually forces people to stop relying on her, and forces her to gradually remove herself from society (Kass 2004). Since this argument depends on certain contingent facts about our social and psychological history, we could call it the argument from psychosocial history. It claims that ageing is natural in the sense that we have always aged for as long as we have been social animals and that ageing is good because, over time, we have come to depend psychologically on ageing as a component of our social environment.

The second argument is that ageing is a universal, genetically defined human function, and that if we used medicine to avert the ageing process, we would risk defining the entire population as defective or diseased for a major part of their lives. Call this the argument from human nature. Carole Haber, for example, argues that anti-ageing medicines would 'demean and marginalise the very process of growing old' (Haber 2004). Callahan, along similar lines, has argued that natural, deleterious processes like ageing become more frightening or disappointing when we have medicines to combat them (Callahan 1990). Vincent frets that 'if death is a solvable problem, then old age will be a failure' (Vincent 2006). And Sandel has famously argued that the proper attitude to take towards our biological traits is to behold them in wonderment (Sandel 2007). Arguments from human nature claim that ageing is natural in the sense that it is a statistically normal process of human biology and that the normal in this sense is good because of ill consequences that flow from medicalizing or devaluing any aspect of human nature.

Finally, there is the argument from evolution, which has been most famously promoted by Fukuyama (2002). It claims that we have good prudential reasons to resist the temptation to meddle with any characteristic which we have been given through a process of natural selection. What is natural, in Fukuyama's view, is what is evolved, and he considers the natural to be good under that definition because evolution can be relied on to provide us with good results.

In my view, the argument from evolution is, on its surface, easily the most plausible of the three arguments in favour of ageing, and so I will address this argument in what remains of this paper. $^{2}$

\section{The Argument from Evolution}

Fukuyama's version of the argument from evolution is not intended to apply only to interventions against ageing, but to interventions involving any widespread genetic

\footnotetext{
$\overline{2}$ There also exists an additional, unrelated argument which relates evolution to the ethics of ageing: that intervention against ageing would slow or halt the evolution of the species, worsening the lives of future generations. I believe this argument, too, is mistaken, since we are no longer evolving through processes of natural selection that would be impeded by anti-aging technologies (Powell 2011). But in any case, it is outside of the scope of this paper.
} 
trait, including cognition, physical traits, and disease resistance. On his view, even if we have traits that appear to be obviously harmful according to current theories of human welfare, we ought to trust that evolution provided us with these traits for good reason:

There are good prudential reasons to defer to the natural order of things and not to think that human beings can easily improve on it through causal intervention. This has proven true with regard to the environment: ecosystems are interconnected wholes whose complexity we frequently don't understand, building a dam or introducing a plant monoculture into an area disrupts unseen relationships and destroys the system's balance in totally unanticipated ways. So too with human nature ... doing nature one better isn't always that easy, evolution may be a blind process, but it follows a ruthless adaptive logic that makes organisms fit for their environments. (Fukuyama 2002)

Erik Parens has put a similar argument into print, echoing Fukuyama's suggestion that nature is better than we are at assessing which traits are good and which traits are bad:

Nature does not have the same sort of short-term economic interests human beings do. Human beings are no more just like every other part of nature than genetic technologies are just like every other technique that humans have used to mould germ lines. As surely as it would be a mistake today to think that only the invisible hand of nature governs evolution, so, too, would it be a mistake to think that the hand of the market will invisibly guide us to some pre-ordained good. (Parens 1995)

Two premises are exposed in these arguments. First, that every evolved human trait is the result of an optimising process, and second, that the optimising nature of a process gives us strong prudential reasons to trust in its results, even if we do not like those results very much.

I wish here to challenge both of these premises. So the first thing to do, in assessing the argument from evolution, is to determine whether or not ageing really has evolved through a process which is generally optimific.

\section{The Evolutionary Biology of Ageing}

Ageing is by no means a unitary process. Although our understanding of the biology of ageing is still very young, we have already identified dozens of mechanisms which generate the pattern of symptoms we refer to as ageing, and these myriad symptoms are markedly distinct from one another in terms of their function and their evolutionary origins.

Allow me to take two processes as examples: deleterious genes and oxidative stress.

\subsection{Deleterious Genes}

There are, so far as we know, no genes which function to age our bodies, but our genome hosts an array of genes that can become harmful as we grow older (Kirkwood 
2002). We are born with all of the harmful genes we will ever possess, give or take a small number of mutations which can occur through radiation or mistakes in replication. The reason that these genes can become harmful late in life, but not early on, is that genes are not all expressed all of the time, in all tissues. That is, some genes are not active in creating proteins unless they are in particular parts of the body, in particular stages of development.

Human beings get much sicker as they get old. Instead of a gradual winding down of activity, we suffer an ever-increasing range of maladies-cancers, infectious, environmental and heritable diseases, and these ailments constitute much of what we consider to be 'old age'.

Some of the increase in disease is due to a depletion of the immune system which is caused by 'immunosenescence' - a process through which the immune system grows weaker with age, causing the body to be less capable of repelling disease. In fact, as we age beyond 80, our risk of dying increases primarily due to an increasing risk of bacterial or viral infections (Pawelec 2006). Many of our genes seem to age us in this way, by doing less to defend us against illness or disability as we get older.

It is now known that there are genes which create a predisposition to a number of cancers, such as breast cancer. Many of these genes are 'silenced' until late in life, when they begin to function in a harmful way (Leslie 2006). And different versions of the same gene become active at different ages; for example, the apolipoprotein-E (APOE) gene has a common variant that changes the average age of onset of Alzheimer's disease from 84 to 68 years of age (Corder et al. 1993).

As well as genes that allow the emergence of acute diseases like infections, cancers, and Alzheimer's disease, we have genes that activate to produce chronic, low-level effects that are not categorised as diseases. For example, our bodies have genes for the expression of 'pro-inflammatory' cytokines, which produce the inflammatory response that is part of the immune system. As we age, these genes become dysregulated, causing the body to become chronically inflamed, and this inflammation is thought to be a major process behind a number of important age-related problems, like arthritis, arthero-sclerosis, dementia, osteoporosis, and heart disease (Capri 2006).

Some of our late-onset genes reflect a kind of evolved trade-off between different survival-affecting processes. For example, certain genetic processes cause elderly people to undergo a decrease in insulin-like growth factor 1, or IGF-1; this decrease leads them to have decreased muscle mass and bone density, but also protects against cancer by inhibiting the growth of tumours (Capri 2006). Proponents of the argument from evolution would likely wish to argue that this protective factor is an example of evolution's 'blind logic'. I will return to this point below.

\subsection{Oxidative Stress}

It has been thought for a long time that the chemical oxidation of cells and cell nuclei is one of the major forms of age-related tissue damage. In 1954, the 'free radical theory of ageing' advanced the idea that all of the deleterious effects of ageing were caused by these oxidative reactions (Harman 2006). 'Free radicals'-reactive molecules containing oxygen, such as hydrogen peroxide - react with molecules in the cells to oxidise them, and this damages the cells. Antioxidant enzymes in the liver and 
elsewhere in the body serve to safely remove free radicals from the body but the purification process is not perfect, and the free radicals are able to damage the organs before they are completely expelled (Holliday 1997).

According to Harman's mitochondrial version of this theory, free radicals enter the body not only from the external environment but also as an essential byproduct of respiration, the process in which our mitochondria produce energy from food and oxygen. These free radicals oxidise both the cells and the mitochondria inside the cells. And as the mitochondria become damaged, they get worse at repairing the cellular damage, and so 'oxidative stress' accumulates in the tissues, until finally the cell falls apart. According to Harman, this accumulation of damage is the main process which causes the symptoms of ageing (Harman 2006). This last claim remains controversial, and indeed there is no firm consensus that any of the damage is caused by respiration, but there is now a strong consensus that oxidative stress is one of the key processes in human ageing (Lapointe 2010).

There is a range of evidence showing how oxidative stress contributes to the symptoms of old age. For example, the neurons of Alzheimer's disease patients show oxidative stress (Ghanbari et al. 2004), and it has also been shown that high levels of oxidation are present in the brains of Parkinson's syndrome patients (Beal 1996) and in the hearts of those with heart failure (Romero-Alvira and Roche 1996). Oxidative stress has also been associated with the formation of cancers, as tumours can form when the DNA in cell nuclei is damaged (Bartsch 2006; Federico et al. 2007).

However, oxidative stress also seems to act against cancer formation in one way. Aged, oxidised cells form a barrier in the body which stops fast-replicating tissues such as cancers from spreading (Lynch 2004). In this way, senescence prevents cancer-another mechanism by which it could be claimed that evolution has selected for us the best balance of traits to promote longevity.

\subsection{How did These Processes Evolve?}

It should be apparent by now that oxidative stress and deleterious genes cannot have evolved in the same way. Our protozoan ancestors did not have an APOE gene or a gene for breast cancer; these genes must have been introduced during the process of evolution. On the other hand, free radicals have been oxidising cells since the very beginning of our evolution, since they are ubiquitous in our environment. Hence there must be (at least) two explanations for emergence of both of these groups of processes.

It may seem puzzling that evolution has introduced genes which, by ageing us, cause us to become weaker and to eventually perish. Peter Medawar, in his 1951 inaugural lecture at University College, argued for a simple solution to the puzzle: that strongest force of natural selection affects those genes which become active prior to an individual's death. Since we humans died very young for the bulk of our evolutionary history, late-acting deleterious genes would not have impeded an individual's chance of surviving and reproducing, and so these genes were not selected against, and they gradually accumulated in the genome over time. Indeed, as George Williams later pointed out, some of these genes may have been actively promoted if they were beneficial in early life before becoming harmful in old age (Williams 1957). But as human beings became more organised and began to live longer, these 
genes began to produce harmful effects on the longest-lived individuals. This goes some way to explaining why we have so many genes which become harmful in the later stages of life. ${ }^{3}$

This explanation is not quite sufficient, however, to explain why we experience ageing due to oxidative stress. Our cells do not oxidise because harmful genes accrued in our genome; we oxidise because we are constantly encountering free radicals, and so we still need to explain why we failed to evolve defences against oxidation, as some animals did. The longest-lived non-colonial animal, the ocean quahog Arctica islandica, lives for at least 400 years, and it appears to have evolved a much greater resistance against oxidative stress than human beings in the form of natural antioxidant chemicals (Abele et al. 2008; Ungvari et al. 2011). As well as these endogenous antioxidants, clams have evolved to have a very low metabolic rate and a correspondingly low rate of activity and growth, meaning that fewer free radicals are produced by the mitochondria, reducing the endogenous source of oxidative ageing.

Nearly every time one gene is selected at the expense of another, it will be a case of a tradeoff: something good being exchanged for something better. As Williams pointed out in his seminal paper, very few animals in nature survive long enough to reach old age. In an environment that includes predation and infectious disease, natural selection will therefore select traits that take effect earlier in life rather than later, and this will frequently mean that traits that are beneficial in old age are sacrificed (Williams 1957). Kirkwood takes this line of reasoning much further suggesting that natural selection very frequently makes such tradeoffs between longevity, fecundity, and capacities for active behaviours like food-seeking or selfdefence (Kirkwood 2002). A. islandica, for example, could afford to invest all its evolutionary chips in cell maintenance and repair because it reproduces sparingly and moves very little.

The reason we age, then, is partly because we have failed to evolve sufficient defences against our environment causing our bodies to physically break down as time passes. It is partly because our evolution has preferred to produce a metabolic rate which is high enough to allow an active lifestyle but which thereby produces more endogenous free radicals. And it is partly because evolution has not, and will not, rid us of our late-acting deleterious mutations. And these failures of evolution are predictable outcomes of the essential nature of the selective process. These ideas are now supported by a consensus of scientists. In a position paper co-signed by 52 biologists of human ageing, Olshansky claims that 'aging is a product of evolutionary neglect, not evolutionary intent' (Olshansky et al. 2002).

These explanations, on their face, pose a fairly serious threat to the argument from evolution, at least as it is applied to the process of ageing. Ageing is not the result of an optimising process, it is merely a byproduct of an optimising process. Even if evolution is a 'blind watchmaker', to use Richard Dawkins' metaphor, ageing does not seem to be part of the watch. Caplan suggests that this is fatal for the argument

\footnotetext{
${ }^{3}$ It should be clear at this stage that a gene can be 'harmful' despite improving the evolutionary fitness of an individual: that is, the individual's chance of contributing genes to the next generation. Harm and health are necessarily defined in the context of human norms and goals, which are not always aligned with the propagation of one's genes; so evolution can promote genes that reduce an individual's health and flourishing.
} 
from evolution, since- he says - the arguments of philosophers like Fukuyama and Parens depend on the idea that evolved traits must necessarily 'advance the evolutionary success of a species or population' (Caplan 2005). ${ }^{4}$

I think we need to be a little more careful than this. In the first place, virtually no traits exist in order to advance the success of the population as a whole, because the great majority of selective forces operate at the level of the individual (Williams 1972; Maynard Smith 1964). So the most reasonable version of the argument from evolution would depend only on the idea that evolved traits must advance the survival and reproductive successes of individuals.

And we do not yet have cause to reject the idea that ageing has advanced the evolutionary success of human individuals. Proponents of this view might object that when we decide to neglect some good, it is usually in order that we can direct our attention elsewhere. If the traits of senescence accrued in the genome through a process of evolutionary neglect, that may mean that some other beneficial trait was produced at the expense of long youth; and perhaps we cannot throw out the chaff (ageing) without losing the wheat (beneficial adaptations). For example, it could be that allowing cellular oxidation is the only tradeoff which would allow high rates of activity along with a relatively low susceptibility to cancer.

If human senescence is the price we have paid for our adaptive traits, like activity and cognitive capability, then perhaps there is a 'ruthless adaptive logic' to ageing after all-perhaps age has evolved as the necessary byproduct of an optimising process. And perhaps proponents of the argument from evolution might also point to the direct benefits of ageing: the cancer-protecting upsides of our most deleterious genes and of the process of cellular oxidation. These suggestions should seem implausible, but they are not certain to be false. If we are to completely reject the argument from evolution, we need to say a little more than Caplan does.

\section{Addressing the Argument from Evolution}

One argument which a number of authors have made concerns the concept of fitness. It seems correct, in the broadest strokes, to say that it would be wrong to equate the goals of evolution with our own prudential goals, since individual fitness, in an evolutionary sense, often fails to correspond to the qualities that human beings value (Powell and Buchanan 2011).

Imagine a gene which makes a person 5\% less fertile but twice as happy. This gene confers no harm to a person who plans to have only two children, or who can support only two children on their income. For the vast majority of Earth's history, this gene would have been selected against in every species, so genes like this one will have been slowly eradicated from every genome. But most modern humans, who do not wish (and cannot afford) to go anywhere near their full reproductive potential, would wish to have this gene. Evolution, it seems, drives us toward outcomes which we might sincerely and unanimously wish to avoid - and ageing must certainly be in the category of traits which do not serve our individual goals.

\footnotetext{
${ }^{4}$ In fact, very few (if any) traits exist in order to advance the success of the species as a whole.
} 
This, however, is a weak counter argument against the argument from evolution. Writers like Fukuyama and Parens appeal to the idea that evolution has a wisdom that far outstrips our own. Callahan and Parens, in a different article, suggest that the 'aspiration to engineer human beings [is] a misguided attempt to equal the creativity of nature' (Callahan and Parens 1995). If nature is indeed wiser, more farsighted and more creative than we mere humans, then our own nearsighted goals, including happiness, health, and even individual survival, might be at odds with nature's grand plan. It is impossible to argue against this kind of claim by appealing to the wisdom of our actual personal aims. If nature is smarter, then anything I say in defence of my own aims will be the mere product of my own myopic inadequacy.

Powell and Buchanan argue against what they call the 'wisdom of nature' argument by appealing to a long list of human characteristics which are clearly examples of 'poor biological design': for example, the routing of the male urethra through the prostate gland, or the blind spot in the retina (Powell and Buchanan 2011). And while their argument is compelling, it is on weaker ground when we are uncertain of the evolutionary function of a given genetic trait or tradeoff. In these cases, a proponent of the argument from evolution might just suggest that our limited understanding of evolutionary biology is obscuring the true benefit of these apparent biological flaws. And nowhere is this problem more pronounced in the case of human ageing, where we do not even understand all of the functional processes that make us grow old, much less the genetics and fitness benefit of each evolved trait and evolutionary tradeoff.

So let us suppose for the sake of argument that the argument from evolution holds true in the general case: that we have strong prudential reasons to avoid using modern techniques to enhance our cognitive capacities, make cosmetic genetic modifications, or to avoid disease. Let us share Fukuyama's distrust of human assessments of what is good and share his trust in the beneficent nature of the process of evolution. Also, following from the preceding section, let us share in the view that even processes of evolutionary neglect can be something that we ought to view as trustworthy in this sense.

Even if we make these rather generous leaps in favour of the argument from evolution, the argument still fails on two counts.

\subsection{Our Environment is Now Changing Very Rapidly}

Natural selection cannot equip us to deal with environmental factors which were not present for the duration of our evolutionary history. For example, so far as we know, this is the first time that the world has begun to be overpopulated. Relative to the rate of evolution, we have only been evolving alongside schools, hospitals, and even farms for the blink of an eye. Any traits that the process of evolution has conferred on us make sense only for an environment which has recently been disrupted or destroyed. Entire species have become extinct for exactly this reason; the dinosaurs' genomes did not equip them to survive an unprecedented meteor strike. Nor have our own genes adapted us for a future of overpopulation and hierarchical life in a postindustrial world.

No matter how much wisdom and logic there is in the process of evolution, it cannot have the power to foresee and defend us against rapid alterations in the 
environment. No matter how unreliable and unwise our own interventions may be, we may be forced to rely on them to contend with an environment which can change radically within a single generation. The argument from evolution assumes some degree of continuity in environmental circumstances, but at present there are strong discontinuities in the structure of our world. Given these changes, it would be foolish to place too much trust in the adaptive quality of traits that evolved across aeons of nomadic hunting and gathering. Or, as Bostrom and Sandberg put it,

"Hunting, gathering of fruit and nuts, courtship, parasites and hand-to-hand combat with wild animals and enemy tribes were elements of the [environment of evolutionary adaptedness]; speeding cars, high levels of trans fats, concrete ghettos, and tax return forms were not." (Bostrom and Sandberg 2009)

One of the effects of overpopulation is that birth rates become depressed, leading to an increase in the proportion of society that is old. And hence one of the biggest threats facing the world is the increasing burden of medical care and welfare support for the retired elderly population. This threat is completely unprecedented in human history, in terms of its scale and likely impact. And it could be mitigated significantly if people could live a higher percentage of their lives in a youthful state, allowing them to care for themselves and even contribute to the economy. Given that we have no reason to have faith in an evolutionary solution to this serious problem, the argument from evolution gives us little reason to refuse the intervention of medical science.

\subsection{We Can Delay the Onset of Ageing Without Eliminating it}

Let us suppose what is quite improbable: that many or even most aspects of the ageing process evolved as necessary byproducts of more genuinely adaptive traits. Remember too that we are supposing rather unreasonably that the tradeoffs made between these processes were in every case the most prudent, farsighted tradeoffs available, according to the ineffable aims of the evolutionary machine. Let us finally suppose that there will be no sharp discontinuities in our external environment, and that evolution will continue to serve us well.

Even if all these things were true, there are a number of ways that ageing can be diminished that do not seem to run contrary to the argument from evolution. Let's start with the simplest, most old-fashioned way to eliminate ageing, which is to die young (leaving a beautiful corpse). Nobody would suggest that dying young violates what is natural, or throws a delicate evolved system out of balance. Dying young has its own particular downsides, but it suggests a more general, practically useful point: since ageing is a process which happens over time, and since we live for different amounts of time, it cannot be true that human flourishing or even evolutionary success depends on some particular amount of ageing taking place.

It is also true that people age at different rates, depending on their environment and genetics. No calamity ensues when a person ages well, when their bodies are less oxidised and less ravaged by malfunctioning genes than the bodies of others in the same cohort. If we are depending on the wisdom of senescence, it is clear that it doesn't matter how quickly we age or how much we age before we die. This suggests that even the most committed proponent of the argument from evolution should be open to the use of certain kinds of interventions against ageing. Let me give two brief examples. 
First, the process of cellular oxidation depends on the concentration of free radicals in our environment and in our bodies. This is why cigarette smoke accelerates ageing in human skin, for example (Bernhard et al. 2007). Existing antioxidant drugs do not really succeed in reducing oxidative stress, but scientists are optimistic that novel drugs will eventually be developed which can reduce or eliminate oxidative ageing (Pun et al. 2009). By eliminating free radicals from our environment and our bodies, for example by developing novel antioxidant drugs, we could slow the process of oxidative ageing significantly.

Now, it is not as though there are no risks involved in eliminating oxidative ageing; for one thing, as I mentioned above, this might result in a slight increase in cancer rates at old age, as the 'barrier' of oxidised cells is diminished. It may also turn out that oxidation plays a role in eliminating pathogens, and infection by bacteria and other parasites may thus be increased as oxidation is diminished (Bogdan 2001). And there could be other unforeseen effects, just as Fukuyama suggests. But eliminating free radicals is essentially an environmental manipulation. Whether we do it by taking antioxidant pills or by moving to the country to take in cleaner air, it is chemically the same thing. We have evolved through a range of environmental conditions, with a host of different oxidative stressors - indeed, the skeletons of early human beings show that air pollution was extreme for much of our evolutionary history (Yang and Omaye 2009). Any reduction in free radicals, then, is a change which ought to be well within the parameters of our evolutionary environment. This kind of manipulation does not second-guess our evolutionary design; to the contrary, it expresses faith that our evolution has provided us with the capacity to flourish in a range of different oxidative environments.

Second, it seems that the component of ageing that is related to deleterious genes can be slowed using the body's evolved response to low-calorie diets. In the $1930 \mathrm{~s}$, scientists observed that rodents which were fed a diet with $20 \%-40 \%$ fewer calories (but equivalent in other nutrients) would live much longer than their freely-fed counterparts (Bordone 2005). This finding has been repeated in worms, flies, yeast and rhesus monkeys, and there seems to be a modest effect in human beings as well, which researchers are currently attempting to maximise (Everitt et al. 2010). Calorie restriction seems to slow the changes in gene expression that occur with age, and as a result it increases lifespan by delaying the onset of evolved age-related disorders like diabetes, cancer and heart disease (Lee 1999).

The hypothesis that is currently used to explain the evolution of this effect is that we have evolved with the capacity to go into a 'maintenance mode' during periods of food scarcity, so that we can stay young long enough to reproduce once food becomes abundant again (Shanley 2000). If this hypothesis or something similar is correct, then it weighs heavily against the argument from evolution. It is only by chance that we currently default to eating more calories and growing old slightly sooner. During some periods of our evolutionary history, it was clearly the case that food was scarce (otherwise this trait would never have evolved), and during others it was abundant. Given these facts, it is not clear that the argument from evolution provides any advice as to whether we should eat calorie-rich or calorie-restricted diets. Whichever option we choose, we will be making a choice about the rate at which we age. And once again, whichever option we choose, we could claim that we were expressing faith in the ineffable wisdom of the blind watchmaker. 


\section{Closing Remarks}

I have given much more ground to Fukuyama and Parens here than is really appropriate. In reality, it will probably turn out that very few of our beneficial adaptations are really unable to coexist with reductions in the ageing process. And we do not have good reason to place as much faith in evolutionary wisdom as the argument from evolution does, especially in the case of traits that evolve as a matter of evolutionary neglect.

However, even when we make every possible concession to the argument from evolution, it seems to fall apart in the case of interventions like the ones I have discussed here, which make changes to our external or internal environment in order to slow the chemical aspects of ageing, or which harness evolved aspects of our biology in order to slow the genetic processes of ageing. In these cases, there is simply nothing for proponents of the argument to object to.

Of course, we cannot mount this sort of defence in favour of all of the different technological strategies for slowing or halting the evolved processes of ageing. The existence of animals like the American lobster and the ocean quahog prove that genes exist which can significantly repair oxidative damage; using genetic engineering techniques, these genes could be inserted in the genome, and the genes which put us at risk as we age for dementia, or cancer, could be altered or eliminated. These sorts of interventions will inevitably become possible as medical technology and the sciences of human genetics and gerontology advance. And there is no reasonable way to reconcile the argument from evolution with the development of radical interventions such as these.

But even in cases where anti-ageing technology moves beyond the bounds of our historical evolutionary environment, the argument from evolution fails because our broader environment is changing so rapidly. Given that our caveman genes have been plunged into a world of supermarkets, chemotherapy, antibiotics, and overpopulation, it makes little sense to appeal to the wise plans that were laid in by the evolutionary process long before the agricultural revolution. Thus, wherever our biological limits prevent us from contending with our rapidly changing environment, it will be appropriate to seek genetic remedies. It is true that we have no reason to think these remedies will produce only the desired and expected effects, and Fukuyama is right to point out that we have a long history of biological intervention gone awry. But equally, we have no reason to think that our genetic status quo will defend us against rapid fluctuations in the environment. Unexpected ill-consequences will likely emerge, no matter what decisions we take.

With all this in mind, reasonable people should reject the evolutionary argument in favour of growing old. In my view, the remaining arguments in favour of ageing fare even worse, when held up to close scrutiny, but I will leave that discussion for another time.

\section{References}

Abele, D., Strahl, J., Brey, T., \& Philipp, E. E. (2008). Imperceptible senescence: ageing in the ocean quahog Arctica islandica. Free Radical Research, 42(5), 474-480. 
Bartsch, H. (2006). Chronic inflammation and oxidative stress in the genesis and perpetuation of cancer: role of lipid peroxidation, DNA damage, and repair. Langenbeck's Archives of Surgery, 39(5), 499-510.

Beal, M. F. (1996). Mitochondria, free radicals, and neurodegeneration. Current Opinion in Neurobiology, $6(5), 661-666$.

Bernhard, D., Moser, C., Backovic, A., \& Wick, G. (2007). Cigarette smoke-an aging accelerator. Experimental Gerontology, 42(3), 160-165.

Bodnar, A. G. (2009). Marine invertebrates as models for aging research. Experimental Gerontology, 44(8), 477-484.

Bogdan, C. (2001). Nitric oxide and the immune response. Nature Immunology, 2(10), 907-916.

Bordone, L. (2005). Calorie restriction, SIRT1 and metabolism: understanding longevity. Nature Reviews. Molecular Cell Biology, 6, 298-305.

Bostrom, N., \& Sandberg, A. (2009). The wisdom of nature. In J. Savulescu \& N. Bostrom (Eds.), Human enhancement (pp. 375-416). Oxford: Oxford University Press.

Callahan, D. (1990). What kind of life: the limits of medical progress. Washington, DC: Georgetown University Press.

Callahan, D., \& Parens, E. (1995). The ends of medicine: shaping new goals. Bulletin of the New York Academy of Medicine, 72(1), 95-117.

Caplan, A. L. (2005). Death as an unnatural process. EMBO Reports, 6, S72-S75.

Capri, M. (2006). The genetics of human longevity. Annals of the New York Academy of Sciences, 1067(1), 252-263.

Corder, E., Saunders, A., Strittmatter, W., Schmechel, D., Gaskell, P., Small, G., et al. (1993). Gene dose of apolipoprotein E type 4 allele and the risk of Alzheimer's disease in late onset families. Science, 261 (5123), 921-923.

Everitt, A. V., Heilbronn, L. K., Morris, B. J., Brown-Borg, H. M., Merry, B. J., Simpson, S. J., et al. (2010). Conclusion: human calorie restriction and anti-aging therapy. In A. V. Everitt, S. I. S. Rattan, D. G. Couteur, \& R. Cabo (Eds.), Calorie restriction, aging and longevity (pp. 311-318). Dordrecht: Springer.

Federico, A., Morgillo, F., \& Tuccillo, C. (2007). Chronic inflammation and oxidative stress in human carcinogenesis. International Journal of Cancer, 121(11), 2381-2386.

Fossel, M. (1998). Telomerase and the aging cell: implications for human health. JAMA: The Journal of the American Medical Association, 279(21), 1732-1735.

Fukuyama, F. (2002). Our posthuman future: consequences of the biotechnology revolution. New York: Farrar, Straus and Giroux.

Ghanbari, H. A., Ghanbari, K., Harris, P. L. R., Jones, P. K., Kubat, Z., Castellani, R. J., et al. (2004). Oxidative damage in cultured human olfactory neurons from Alzheimer's disease patients. Aging Cell, $3(1), 41-44$.

Haber, C. (2004). Life extension and history: the continual search for the fountain of youth. The Journals of Gerontology. Series A, Biological Sciences and Medical Sciences, 59(6), B515-B522.

Harman, D. (2006). Free radical theory of aging: an update: increasing the functional life span. Annals of the New York Academy of Sciences, 1067(1), 10-21.

Harris, J. (1970). The value of life: an introduction to medical ethics. London: Routledge.

Holliday, R. (1997). Understanding ageing. Philosophical Transactions of the Royal Society of London Series B. Biological Sciences, 352(1363), 1793-1797.

Kass, L. (2004). L'Chaim and its limits: why not immortality. In S. G. Post \& R. H. Binstock (Eds.), The fountain of youth: cultural, scientific, and ethical perspectives on a biomedical goal. Oxford: Oxford University Press.

Kirkwood, T. B. L. (2002). Evolution of ageing. Mechanisms of Ageing and Development, 123(7), 737-745. Lapointe, J. (2010). When a theory of aging ages badly. Cellular and Molecular Life Sciences, 67(1), 1-8.

Lee, C. (1999). Gene expression profile of aging and its retardation by caloric restriction. Science, 285 (5432), 1390-1393. New York, NY.

Leslie, M. (2006). The age of cancer. Science of Aging Knowledge Environment (10), nf16.

Lynch, M. D. (2004). The role of cellular senescence may be to prevent proliferation of neighboring cells within stem cell niches. Ann NY Acad Sci, 1019, 191-194.

Mauron A (2005) The choosy reaper. EMBO reports, 6 Spec No, S67-71

Maynard Smith, J. (1964). Group selection and kin selection. Nature, 201(4924), 1145-1147.

Olshansky, S. J., \& Carnes, B. A. (2001). The quest for immortality: science at the frontiers of aging. New York: W.W. Norton.

Olshansky, S. J., Hayflick, L., \& Carnes, B. A. (2002). Position statement on human aging. The Journals of Gerontology Series A. Biological Sciences and Medical Sciences, 57(8), B292-B297. 
Parens, E. (1995). Should we hold the (germ) line. The Journal of Law Medicine \& Ethics, 173, $173-176$. Pawelec, G. (2006). Human immunosenescence: does it have an infectious component. Annals of the New York Academy of Sciences, 1067(1), 56-65.

Powell, R. (2011). The future of human evolution. The British Journal for the Philosophy of Science, 0, 1-31.

Powell, R., \& Buchanan, A. (2011). Breaking evolution's chains: the prospect of deliberate genetic modification in humans. The Journal of Medicine and Philosophy, 36(1), 6-27.

Pun, P. B. L., Gruber, J., Tang, S. Y., Schaffer, S., Ong, R. L. S., Fong, S., et al. (2009). Ageing in nematodes: do antioxidants extend lifespan in Caenorhabditis elegans. Biogerontology, 11(1), 17-30.

Romero-Alvira, D., \& Roche, E. (1996). Cardiomyopathies and oxidative stress. Medical hypotheses, 47 (2), 137-144.

Sandel, M. (2007). The case against perfection: ethics in the age of genetic engineering. Cambridge, MA: Harvard University Press.

Shanley, D. (2000). Calorie restriction and aging: a life-history analysis. Evolution, 54(3), 740-750.

Tomás-Loba, A., Flores, I., Fernández-Marcos, P. J., Cayuela, M. L., Maraver, A., Tejera, A., et al. (2008). Telomerase reverse transcriptase delays aging in cancer-resistant mice. Cell, 135(4), 609-622. doi:10.1016/j.cell.2008.09.034.

Ungvari, Z., Ridgway, I., Philipp, E. E., Campbell, C. M., McQuary, P., Chow, T., et al. (2011). Extreme longevity is associated with increased resistance to oxidative stress in Arctica islandica, the longestliving non-colonial animal. The Journals of Gerontology Series A, Biological Sciences and Medical Sciences, 66(7), 741-750.

Vaupel, J. W. (2010). Biodemography of human ageing. Nature, 464(7288), 536-542.

Vincent, J. (2006). Ageing contested: anti-ageing science and the cultural construction of old age. Sociology, 40(4), 681-698.

Williams, G. C. (1957). Pleiotropy, natural selection, and the evolution of senescence. Evolution, 11(4), 398-411.

Williams, G. C. (1972). Adaptation and natural selection: a critique of some current evolutionary thought. Princeton: Princeton University Press.

Williams, B. (1976). Problems of the self. Philosophical papers 1956-1972. Cambridge: Cambridge University Press.

Yang, W., \& Omaye, S. T. (2009). Air pollutants, oxidative stress and human health. Mutation Research, Genetic Toxicology and Environmental Mutagenesis, 674(1-2), 45-54. 